\title{
BMJ Open Temporal trends of COVID-19 mortality and hospitalisation rates: an observational cohort study from the US Department of Veterans Affairs
}

\author{
Miao Cai (D) , ${ }^{1,2}$ Benjamin Bowe, ${ }^{1,2,3}$ Yan Xie (D) , ${ }^{1,2,3}$ Ziyad Al-Aly (D) ${ }^{1,2,4,5,6}$
}

To cite: Cai M, Bowe B, Xie $\mathrm{Y}$, et al. Temporal trends of COVID-19 mortality and hospitalisation rates: an observational cohort study from the US Department of Veterans Affairs. BMJ Open 2021;11:e047369. doi:10.1136/ bmjopen-2020-047369

- Prepublication history and additional supplemental material for this paper are available online. To view these files, please visit the journal online (http://dx.doi.org/10.1136/ bmjopen-2020-047369).

Received 29 November 2020 Accepted 07 June 2021

Check for updates

(c) Author(s) (or their employer(s)) 2021. Re-use permitted under CC BY-NC. No commercial re-use. See rights and permissions. Published by BMJ.

For numbered affiliations see end of article.

Correspondence to

Dr Ziyad Al-Aly;

zalaly@gmail.com

\section{ABSTRACT}

Objectives To investigate the temporal trends of 30-day mortality and hospitalisation in US Veterans with COVID-19 and 30-day mortality in hospitalised veterans with COVID-19 and to decompose the contribution of changes in the underlying characteristics of affected populations to these temporal changes.

Design Observational cohort study.

Setting US Department of Veterans Affairs.

Participants 49238 US veterans with a positive COVID-19 test between 20 March 2020 and 19 September 2020; and 9428 US veterans hospitalised with a positive COVID-19 test during the same period.

Outcome measures 30 -day mortality rate and hospitalisation rate.

Results Between 20 March 2020 and 19 September 2020 and in COVID-19 positive individuals, 30-day mortality rate dropped by $9.2 \%$ from $13.6 \%$ to $4.4 \%$; hospitalisation rate dropped by $16.8 \%$ from $33.8 \%$ to $17.0 \%$. In hospitalised COVID-19 individuals, 30-day mortality rate dropped by $12.7 \%$ from $23.5 \%$ to $10.8 \%$. Among COVID- 19 positive individuals, decomposition analyses suggested that changes in demographic, health and contextual characteristics, COVID-19 testing capacity, and hospital occupancy rates accounted for $40.2 \%$ and $33.3 \%$ of the decline in 30-day mortality and hospitalisation, respectively. Changes in the underlying characteristics of hospitalised COVID-19 individuals accounted for $29.9 \%$ of the decline in 30-day mortality.

Conclusion Between March and September 2020, changes in demographic and health characteristics of people infected with COVID-19 contributed measurably to the substantial decline in 30-day mortality and hospitalisation.

\section{INTRODUCTION}

Reports from regional health systems and the Centre of Disease Control suggest substantial temporal variations in COVID-19 mortality rates $^{1-3}$; however, a national temporal analysis of mortality and hospitalisation rates accounting for individual-level characteristics is lacking, and the relative contribution of changes in demographic and health characteristics of people infected with COVID-19 to
Strengths and limitations of this study

- National large-scale individual-level data from the US Department of Veterans Affairs which operates the largest integrated healthcare system in the USA.

- Advanced decomposition methods disentangle the influence of changes in demographics and health characteristics on temporal trends of 30-day mortality and hospitalisation rates.

- The study accounted for important but less studied drivers of change in mortality and hospitalisation including contextual variables, testing capacity and hospital occupancy rates.

- The veteran population includes mostly older white men, which may limit the generalisability.

temporal differences in mortality rates is not clear.

A deeper understanding of the changes in hospitalisation and mortality rates and the drivers of such changes in the first wave of the pandemic will aid effort to optimise management of future waves of this global pandemic.

In this work, we leveraged the breadth and depth of the US Department of Veterans Affairs (VA) electronic healthcare databases to describe temporal changes in mortality rates and hospitalisation among COVID19-positive veterans, and temporal changes in mortality rates of hospitalised veterans with COVID-19. We then decomposed the contribution of changes in demographic, health and contextual characteristics to these temporal changes.

\section{METHODS}

Identification of COVID-19 test-positive

individuals

Using the comprehensive COVID-19 Shared Data Resource (CSDR) ${ }^{45}$ developed by the Department of VA, we identified unique US veterans with their first laboratory-confirmed COVID-19-positive test between 20 March 
2020 and 19 September 2020. The CSDR captures COVID-19 cases based on laboratory results that comply with Centers for Disease Control and Prevention standards, including 2019-nCOV reverse transcription-PCR Diagnostic Panel and the SARS-CoV-2 Multiplex Assay, or human-confirmed case review. ${ }^{5}$ The VA had its first COVID-19-positive patient on 2 March 2020. In this study, 20 March 2020 was selected as the first day of observation where it was the first day that VA had more than 100 COVID-19-positive patients nationally, facilitating stabilisation of rate calculations. We selected 19 September 2020 as the last day of observation to ensure 30 days of follow-up for observation of outcomes.

\section{Data sources}

Data were obtained from the VA $\mathrm{CSDR}^{4}$ and Corporate Data Warehouse $(\mathrm{CDW}),{ }^{6-18}$ which provides electronic health record information during routine healthcare. Demographic information and dates of death were collected from the CDW SPatient domain. Patient clinical diagnoses, procedures and hospitalisation characteristics were obtained from the CDW outpatient encounter and inpatient encounter domains. Smoking status was obtained from the CDW health factors domain. Laboratory results, including serum creatinine, were obtained from the CDW patient laboratory chemistry domain. Data on height, weight and blood pressure were procured from the CDW vital signs domain. The CDW outpatient pharmacy domain was used to obtain diabetes medication data. The Planning System Support Group Enrollee provided the Federal Information Processing Standard (FIPS) code of residence. The 2015 Area Deprivation Index (ADI) were obtained from the University of Wisconsin. The ADI is a composite measure of a census block group's socioeconomic disadvantage and is constructed from data elements including education, employment, housing quality and poverty measures. ${ }^{19}$

\section{Outcomes}

We examined the temporal trends in (1) rates of 30-day mortality and hospitalisation among those with a positive COVID-19 test, and (2) rates of 30-day mortality among those hospitalised with COVID-19. Thirty-day mortality was defined as all-cause mortality occurring within the 30 days after the participant's first COVID-19 positive test. Hospitalisation is defined by a hospital admission between 5 days before and 30 days after the first COVID-19 positive test.

\section{Participant characteristics}

Race was categorised as white, black and other. Health features included body mass index (BMI) and smoking status. BMI was computed from the last measurements of the participant's height and weight prior to and closest to the first COVID-19-positive test date. Smoking status was categorised as never smoker, former smoker and current smoker, based on the most recent record prior to the first COVID-19-positive test. Comorbidities included
Table 1 Characteristics of the individuals with COVID-19 and hospitalised individuals with COVID-19

\begin{tabular}{|c|c|c|}
\hline Characteristic & $\begin{array}{l}\text { Veterans with } \\
\text { COVID-19 ( } N=49 \text { 238) }\end{array}$ & $\begin{array}{l}\text { Hospitalised } \\
\text { veterans with } \\
\text { COVID-19 }(\mathrm{N}=9428)\end{array}$ \\
\hline \multicolumn{3}{|l|}{ Demographics } \\
\hline $\begin{array}{l}\text { Age (years), median } \\
\text { (IQR) }\end{array}$ & $63.3(49.8-73.1)$ & $70.6(61.2-76.8)$ \\
\hline \multicolumn{3}{|l|}{ Race, n (\%) } \\
\hline White & $29814(60.6)$ & $5054(53.6)$ \\
\hline Black & 16714 (33.9) & $3809(40.4)$ \\
\hline Other & $2710(5.5)$ & $565(6.0)$ \\
\hline Sex (women), n (\%) & $5673(11.5)$ & $527(5.6)$ \\
\hline \multicolumn{3}{|l|}{ Health characteristics } \\
\hline \multicolumn{3}{|l|}{ BMI category, $\mathrm{n}(\%)$} \\
\hline $\begin{array}{l}\text { Underweight }(<8.5 \\
\left.\mathrm{kg} / \mathrm{m}^{2}\right)\end{array}$ & $265(0.5)$ & $83(0.9)$ \\
\hline $\begin{array}{l}\text { Normal weight } \\
\left(18.5-<25.0 \mathrm{~kg} / \mathrm{m}^{2}\right)\end{array}$ & $9939(20.2)$ & $1836(19.5)$ \\
\hline $\begin{array}{l}\text { Overweight (25- } \\
\left.<30 \mathrm{~kg} / \mathrm{m}^{2}\right)\end{array}$ & $15032(30.5)$ & $2922(31.0)$ \\
\hline $\begin{array}{l}\text { Obesity (>18.5 kg/ } \\
\left.\mathrm{m}^{2}\right)\end{array}$ & 24002 (48.7) & $4587(48.7)$ \\
\hline
\end{tabular}

Smoke, $\mathrm{n}(\%)$

\begin{tabular}{|c|c|c|}
\hline Never smoker & $27492(55.8)$ & $4713(50.0)$ \\
\hline Former smoker & $13062(26.5)$ & $2956(31.4)$ \\
\hline Current smoker & $8684(17.6)$ & $1759(18.7)$ \\
\hline Hypertension, (\%) & $30568(62.1)$ & $6347(67.3)$ \\
\hline Diabetes, n (\%) & $13717(27.9)$ & $3695(39.2)$ \\
\hline Cancer, n (\%) & $4558(9.3)$ & $1443(15.3)$ \\
\hline $\begin{array}{l}\text { Cardiovascular } \\
\text { disease, } \mathrm{n}(\%)\end{array}$ & $10399(21.1)$ & $3417(36.2)$ \\
\hline $\begin{array}{l}\text { Cerebrovascular } \\
\text { disease, } \mathrm{n}(\%)\end{array}$ & $5192(10.5)$ & $1836(19.5)$ \\
\hline Dementia, n (\%) & $5350(10.9)$ & $1953(20.7)$ \\
\hline $\begin{array}{l}\text { Chronic kidney } \\
\text { disease, } \mathrm{n}(\%)\end{array}$ & $9573(21.9)$ & $3042(34.9)$ \\
\hline $\begin{array}{l}\text { Peripheral artery } \\
\text { disease, } \mathrm{n}(\%)\end{array}$ & $1411(2.9)$ & $543(5.8)$ \\
\hline HIV, n (\%) & $504(1.0)$ & $141(1.5)$ \\
\hline Pneumonia, n (\%) & $765(1.6)$ & $336(3.6)$ \\
\hline COPD, n (\%) & 7666 (15.6) & $2429(25.8)$ \\
\hline \multicolumn{3}{|l|}{ Contextual factors } \\
\hline \multicolumn{3}{|c|}{ ADI rank category, $\mathrm{n}(\%)$} \\
\hline $0-33.3$ & 10248 (20.8) & $1785(18.9)$ \\
\hline $33.4-366.6$ & $20861(42.4)$ & $3643(38.6)$ \\
\hline $66.7-100$ & $18129(36.8)$ & $4000(42.4)$ \\
\hline \multicolumn{3}{|l|}{ Testing capacity } \\
\hline $\begin{array}{l}\text { COVID-19 testing } \\
\text { capacity (per } 10000 \\
\text { people), mean (SD) }\end{array}$ & $3.1(1.9)$ & $2.8(1.8)$ \\
\hline \multicolumn{3}{|l|}{ Hospital occupancy } \\
\hline $\begin{array}{l}\text { Hospital occupancy } \\
(\%) \text {, mean (SD) }\end{array}$ & $37.0(10.8)$ & $38.1(10.5)$ \\
\hline
\end{tabular}

ADI, Area Deprivation Index; COPD, chronic obstructive pulmonary disease. 
Table 2 30-day mortality and hospitalisation rates in US veterans by 30-day periods, 20 March 2020-19 September 2020

\begin{tabular}{lclll}
\hline Periods & CovID-19 patients & $\begin{array}{l}\text { 30-day mortality, } \\
\text { (total N) }\end{array}$ & $\begin{array}{l}\text { Hospitalisation, } \\
\mathbf{n}(\%)\end{array}$ & $\begin{array}{l}\text { hospitalised } \\
\text { COVID-19 patients, } \mathbf{n}(\%)\end{array}$ \\
\hline 20 March-19 April & 5896 & 13.6 & 33.8 & 23.5 \\
\hline 20 April-19 May & 6685 & 12.3 & 17.2 & 17.0 \\
\hline 20 May-19 June & 4824 & 7.1 & 20.0 & 12.6 \\
\hline 20 June-19 July & 13084 & 4.9 & 17.4 & 11.8 \\
\hline 20 July-19 August & 11874 & 5.2 & 15.8 & 11.1 \\
\hline 20 August-19 September & 6875 & 4.4 & 17.0 & 10.8 \\
\hline Overall & 49238 & 7.2 & 19.1 & 14.8 \\
\hline
\end{tabular}

cancer, cardiovascular disease, cerebrovascular disease, chronic kidney disease, chronic obstructive pulmonary disease (COPD), dementia, diabetes mellitus, HIV, hypertension, peripheral artery disease and pneumonia. Cancer, cardiovascular disease, cerebrovascular disease, dementia, HIV, peripheral artery disease, pneumonia and COPD were identified in the 2 years prior to testing positive for COVID-19 through International Classification of Diseases, 10th Version, Clinical Modification diagnosis codes. ${ }^{1820}$ Chronic kidney disease was defined as baseline estimated glomerular filtration rate (eGFR) lower than $60 \mathrm{~mL} / \mathrm{min} / 1.73 \mathrm{~m}^{2}$. Baseline eGFR was calculated using the Chronic Kidney Disease Epidemiology Collaboration (CKD-EPI) equation ${ }^{21}$ and was assessed as the veteran's last outpatient value prior to the date of first COVID-19 test positive. Participants who had no measurement of baseline eGFR ( $\mathrm{n}=5447,11.1 \%$ for veterans with COVID$19 ; \mathrm{n}=717,7.6 \%$ for hospitalised veterans with COVID19) were assumed to have no chronic kidney disease. Diabetes was defined as any use of antihyperglycaemic medications $^{22} 23$ or incidence of haemoglobin A1C greater or equal to $6.5 \% .^{24}$ Hypertension was defined as median systolic blood pressure greater than or equal to $130 \mathrm{~mm} \mathrm{Hg}$ or median diastolic blood pressure greater than or equal to $80 \mathrm{~mm} \mathrm{Hg}$ in 1 year. ${ }^{25}$ Participants who had no measurement of blood pressure $(n=2699,5.5 \%$ for veterans with COVID-19; $\mathrm{n}=235,2.5 \%$ for hospitalised veterans with COVID-19) were assumed to have no chronic kidney disease. ADI is a composite measure of a geographical location's socioeconomic disadvantage, and ranges from 0 (low disadvantage) to 100 (high disadvantage). County-level ADI of the participants was assigned based on the participant's FIPS code of residence location at the first COVID-19 positive test date. Mean imputation was applied to missing values of covariates including BMI (missing $=111,0.2 \%$ of veterans with COVID-19; missing $=11,0.1 \%$ of hospitalised veterans with COVID-19) and ADI (missing=1303, 2.6\% of veterans with COVID-19; missing $=88,1.0 \%$ of hospitalised veterans with COVID19). COVID-19 testing capacity was calculated as 7-day averages of the number of COVID-19 tests conducted in a hospital system divided by the total number of veterans served in that hospital system in the last calendar year.
Hospital occupancy rate was defined as the percentage of beds occupied by hospitalised patients in a hospital system within a calendar week. COVID-19 testing capacity and hospital occupancy rate were linked to the veterans by the hospital system in which the individuals had their first positive COVID-19 test.

\section{Statistical analyses}

We calculated and plotted 7-day moving averages of crude and standardised 30-day mortality and hospitalisation rates in COVID-19-positive participants, as well as 30-day mortality rates in hospitalised COVID-19-positive participants. The 7-day range included the current day, and the 3 days before and after. Standardised rates were adjusted for age, race, gender, health behaviours (smoking status and BMI), comorbidities and ADI through indirect standardisation. ${ }^{26}$ The standardisation was based on the ratio difference between expected and observed number of outcomes, where the expected number of outcomes was estimated from individual-level logistic regressions.

To understand driving factors of the temporal tends in the outcomes, we decomposed the contribution of the changes in key participant characteristics to changes in the observed rates of outcomes over time. We first constructed individual-level logistic regression models for the different outcomes using four sets of factor domains: demographics (age, race and gender), health characteristics (BMI, diabetes, cancer, cardiovascular disease, cerebrovascular disease, chronic kidney disease, dementia, HIV, hypertension, peripheral artery disease, pneumonia and smoking status), contextual factors (ADI), COVID-19 testing capacity and hospital occupancy rate. Hospital occupancy rate was not included as a predictor of hospitalisation since they are measuring the same variable. For each individual, we then computed the expected probabilities of the outcome based on a participants observed characteristics and under a reference characteristics set, where probability of the outcome was minimised (age was set as 0 , and other categorical variables were set to be the reference group). We estimated the additive contribution of the six sets of factor domains to the estimated rates of the outcome using decomposition analysis. ${ }^{27}$ Then the change in outcome rates between the first (20 March-19 
A

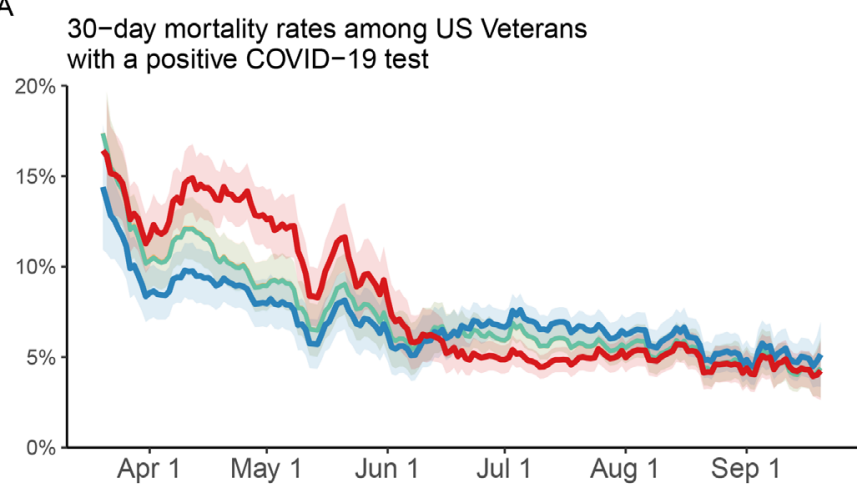

B

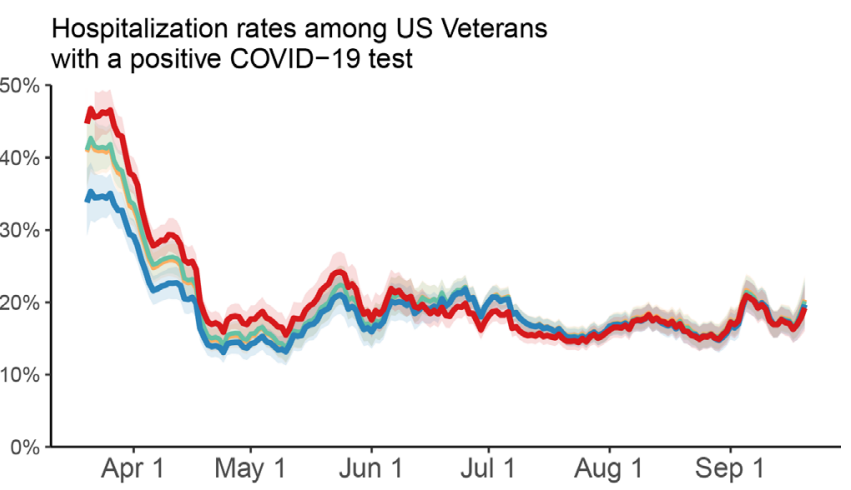

C

30-day mortality rates among hospitalized US Veterans with a positive COVID-19 test

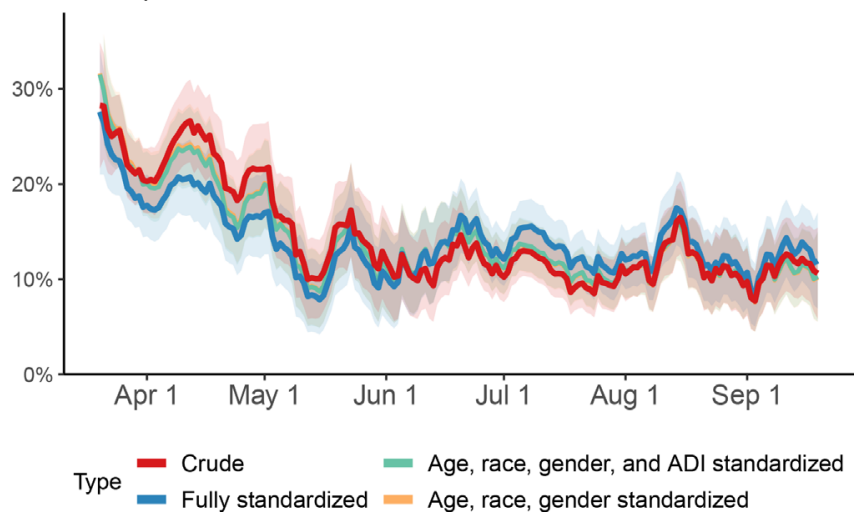

Figure 1 Temporal trends of COVID-19 30-day mortality and hospitalisation among US Veterans. $(A, B)$ Thirty-day mortality and hospitalisation rates in US Veterans who had a positive COVID-19 test ( $n=29$ 528). (C) Thirty-day mortality rate in hospitalised US veterans with a positive COVID-19 test ( $n=6449)$. Fully standardised rates were adjusted for, demographics (age, race and gender), health characteristics (smoking status, Body Mass Index, cancer, cardiovascular disease, chronic kidney disease, dementia, type 2 diabetes mellitus, HIV, hypertension, peripheral artery disease, pneumonia and stroke), contextual factors (ADI), COVID-19 testing capacity and hospital occupancy. ADI, Area Deprivation Index.

April) and the last (20 August-19 September) 30-day periods associated with each domain were calculated by taking the difference of the contributions between the two periods.

All statistical tests were two sided, and a p-value less than 0.05 or a $95 \%$ CI that did not contain unity was considered statistically significant. Statistical analyses and data visualisation were performed using SAS Enterprise Guide V.7.1 and R V.4.0.2. ${ }^{28}$ The participants were not involved in the design, conduct, reporting or dissemination plans of the study.

\section{Patient and public involvement}

No patients were involved in developing the hypothesis, the specific aims or the research questions, nor were they involved in developing plans for design or implementation of the study. No patients were involved in the interpretation or writing up of results.

\section{RESULTS}

Between 20 March 2020 and 19 September 2020, we identified 49238 US veterans who tested positive for COVID-19 and 9428 US veterans hospitalised with COVID-19. Characteristics of the two cohorts are reported in table 1 . Among individuals with COVID-19, the median age was 63.3 years (IQR 49.8-73.1 years); $60.6 \%$ were white, $33.9 \%$ were black, and $11.5 \%$ were women. Among hospitalised individuals, the median age was 70.6 years (IQR $61.2-76.8$ years); $53.6 \%$ were white, $40.4 \%$ were black, and $6.0 \%$ were women.

Temporal trends in 30-day mortality and hospitalisation rates Between 20 March 2020 and 19 September 2020 and among individuals with a COVID-19-positive test, the 30-day mortality rate dropped by $9.2 \%$ from $13.6 \%$ to $4.4 \%$; the hospitalisation rate dropped by $16.8 \%$ from $33.8 \%$ to $17.0 \%$ (table 2 and figure 1). Among hospitalised individuals with COVID-19, the 30-day mortality rate dropped by $12.7 \%$ from $23.5 \%$ to $10.8 \%$ (table 2 and figure 1). After accounting for demographics, contextual factors, health characteristics, COVID-19 testing capacity and hospital occupancy, standardised rates showed consistent decline during the period (figure 1).

Between 20 March 2020 and 19 September 2020 and among hospitalised individuals with COVID-19, we observed consistent decline in healthcare resource use including decline in rates of intensive care unit (ICU) admission, mechanical ventilator use and length of hospital stay (online supplemental table 1). The rate of ICU stay dropped by $4 \%$ from $35.6 \%$ to $31.6 \%$; the rate of mechanical ventilator use dropped by $11.3 \%$ from $20.6 \%$ to $9.3 \%$; the mean length of stay dropped by 4.2 days from 13.8 to 9.6 days.

\section{Predictors of 30-day mortality and hospitalisation}

Adjusted ORs for the association between potential predictors and risk of 30-day mortality and hospitalisation among veterans with COVID-19, as well as risk of 30-day mortality among hospitalised veterans with COVID-19 are presented in table 3. Among veterans with COVID-19, older age, black and other race, male gender, current smoker, diabetes, cancer, cardiovascular disease, dementia, chronic kidney disease, pneumonia, COPD 
Table 3 ORs (95\% Cls) of predictors associated with 30-day mortality and hospitalisation among veterans and hospitalised veterans with COVID-19

\begin{tabular}{|c|c|c|c|}
\hline \multirow[b]{2}{*}{ Characteristics } & \multicolumn{2}{|c|}{ Veterans with COVID-19 } & \multirow{2}{*}{$\begin{array}{l}\text { Hospitalised veterans with } \\
\text { COVID-19 } \\
\text { 30-day mortality }\end{array}$} \\
\hline & 30-day mortality & Hospitalisation & \\
\hline \multicolumn{4}{|l|}{ Demographics } \\
\hline Age & $1.08(1.07$ to 1.08$)$ & $1.02(1.02$ to 1.02$)$ & 1.06 (1.06 to 1.07$)$ \\
\hline \multicolumn{4}{|l|}{ Race (reference=white) } \\
\hline Black & 1.11 (1.01 to 1.22$)$ & $1.64(1.56$ to 1.74$)$ & $1.03(0.90$ to 1.18$)$ \\
\hline Other & 1.33 (1.12 to 1.58$)$ & $1.58(1.42$ to 1.76$)$ & 1.20 (0.92 to 1.57$)$ \\
\hline Sex, women (reference=men) & 0.52 (0.40 to 0.67$)$ & 0.74 (0.67 to 0.82$)$ & $0.72(0.47$ to 1.06$)$ \\
\hline \multicolumn{4}{|l|}{ Health characteristics } \\
\hline \multicolumn{4}{|l|}{ BMI category (reference=normal wt) } \\
\hline Underweight $\left(<18.5 \mathrm{~kg} / \mathrm{m}^{2}\right)$ & 1.03 (0.64 to 1.59$)$ & $1.26(0.92$ to 1.71$)$ & $0.67(0.29$ to 1.38$)$ \\
\hline Overweight $(25-<30$ kg/m²) & 0.89 (0.80 to 1.00$)$ & 0.98 (0.91 to 1.06$)$ & 1.07 (0.90 to 1.29$)$ \\
\hline Obesity $\left(>18.5 \mathrm{~kg} / \mathrm{m}^{2}\right)$ & $1.02(0.92$ to 1.15$)$ & 1.05 (0.98 to 1.13$)$ & 1.24 (1.03 to 1.49$)$ \\
\hline \multicolumn{4}{|c|}{ Smoking status (reference=never smoker) } \\
\hline Former smoker & 1.15 (1.05 to 1.25$)$ & 1.01 (0.96 to 1.07$)$ & $1.11(0.97$ to 1.28$)$ \\
\hline Current smoker & 1.12 (0.99 to 1.27$)$ & 1.11 (1.03 to 1.19$)$ & $1.21(1.00$ to 1.46$)$ \\
\hline Hypertension & $0.87(0.80$ to 0.94$)$ & $1.10(1.04$ to 1.16$)$ & $0.81(0.70$ to 0.92$)$ \\
\hline Diabetes & 1.37 (1.26 to 1.49$)$ & 1.23 (1.16 to 1.29$)$ & 1.15 (1.00 to 1.31$)$ \\
\hline Cancer & 1.10 (0.99 to 1.22$)$ & 1.36 (1.27 to 1.47$)$ & 1.03 (0.88 to 1.21$)$ \\
\hline Cardiovascular disease & 1.17 (1.07 to 1.27$)$ & 1.43 (1.35 to 1.52$)$ & 1.15 (1.00 to 1.31$)$ \\
\hline Cerebrovascular disease & 1.09 (0.98 to 1.20$)$ & 1.38 (1.29 to 1.48$)$ & $1.04(0.90$ to 1.21$)$ \\
\hline Dementia & 1.81 (1.65 to 2.00$)$ & 1.52 (1.41 to 1.63$)$ & 1.37 (1.18 to 1.59$)$ \\
\hline Chronic kidney disease & 1.48 (1.36 to 1.61$)$ & 1.27 (1.20 to 1.35$)$ & 1.47 (1.28 to 1.68$)$ \\
\hline Peripheral arterial disease & 1.09 (0.92 to 1.29$)$ & 1.31 (1.16 to 1.48$)$ & 1.17 (0.92 to 1.47$)$ \\
\hline HIV & 1.05 (0.67 to 1.58$)$ & 1.50 (1.22 to 1.85$)$ & 1.23 (0.71 to 2.03$)$ \\
\hline Pneumonia & 1.44 (1.15 to 1.80$)$ & 2.00 (1.71 to 2.35$)$ & 1.22 (0.90 to 1.62$)$ \\
\hline COPD & 1.21 (1.10 to 1.32$)$ & 1.40 (1.31 to 1.49$)$ & 0.96 (0.83 to 1.11$)$ \\
\hline \multicolumn{4}{|l|}{ Contextual factors } \\
\hline \multicolumn{4}{|l|}{ ADI rank (reference=1-33.2) } \\
\hline $33.3-66.6$ & 0.99 (0.89 to 1.10$)$ & 1.03 (0.96 to 1.10$)$ & 0.94 (0.79 to 1.11$)$ \\
\hline $66.7-100.0$ & 1.04 (0.93 to 1.16$)$ & 1.16 (1.09 to 1.25$)$ & 0.92 (0.77 to 1.09$)$ \\
\hline \multicolumn{4}{|l|}{ COVID-19 testing capacity } \\
\hline $\begin{array}{l}\text { COVID- } 19 \text { testing capacity (per } 10 \\
000 \text { veterans) }\end{array}$ & 0.92 (0.90 to 0.94$)$ & 0.95 (0.94 to 0.96$)$ & 0.90 (0.86 to 0.93$)$ \\
\hline \multicolumn{4}{|l|}{ Hospital occupancy } \\
\hline $\begin{array}{l}\text { Hospital occupancy rate (an } \\
\text { increase of } 10 \% \text { ) }\end{array}$ & 1.05 (1.01 to 1.08$)$ & Not included & 1.08 (1.02 to 1.15$)$ \\
\hline C-statistics & 0.834 & 0.718 & 0.746 \\
\hline
\end{tabular}

ADI, Area Deprivation Index; COPD, chronic obstructive pulmonary disease; eGFR, estimated glomerular filtration rate.

and higher hospital occupancy rate were associated with higher risk of 30-day mortality and hospitalisation; higher COVID-19 testing capacity was associated with lower risk of 30-day mortality and hospitalisation. Among hospitalised veterans with COVID-19, older age, male gender, obesity, current smoker, diabetes, cardiovascular disease, chronic kidney disease, dementia and higher hospital occupancy rate were associated with higher risk of 30-day mortality; higher COVID-19 testing capacity was associated with lower risk of 30-day mortality. The models for 30-day mortality and hospitalisation among those who tested positive, and the model for 30-day mortality among 


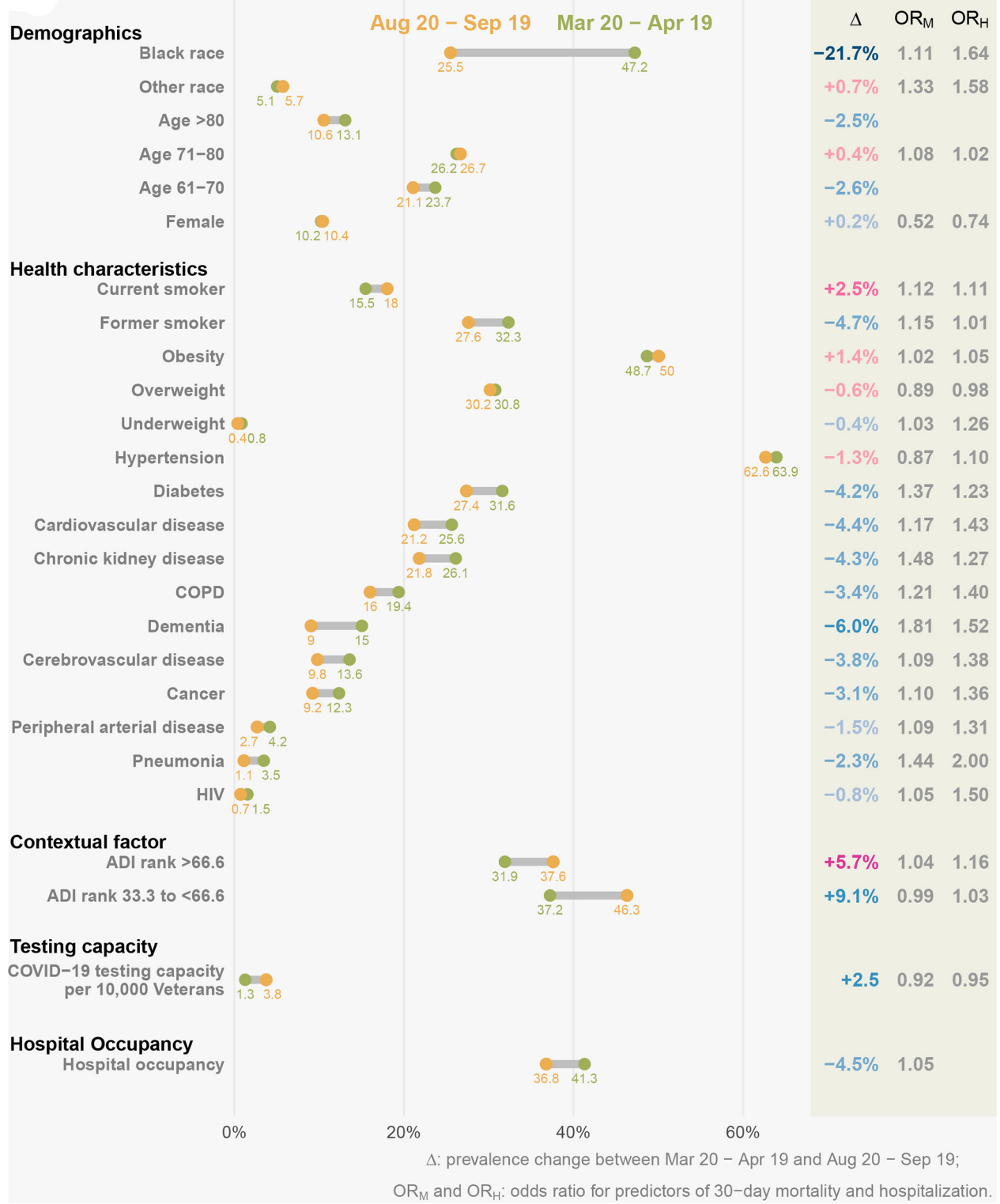

Figure 2 Change in predictors of 30-day mortality and hospitalisation among US veterans with COVID-19 between 20 March and 19 April 2020 and 20 August and 19 September 2020. The yellow dots represent the prevalence of predictors in 20 March-19 April 2020, while the green dots represent the prevalence of predictors in 20 August-19 September 2020. In the delta column, blue text indicates that the change of predictor leads to decrease in mortality and hospitalisation rates, while red text indicates the change of predictor leads to decrease in mortality and hospitalisation rates. ADI, Area Deprivation Index; COPD, chronic obstructive pulmonary disease.

hospitalised achieved reasonably good predictive performance, with the c-statistics of $0.834,0.718$ and 0.746 , respectively. The c-statistics for nested models, showing the predictive performance improvement when adding different variable sets, are included in online supplemental table 2.

\section{Temporal change of predictors of 30-day mortality and hospitalisation}

The demographic, health and contextual characteristics as well as hospital occupancy and testing capacity in each 1-month interval after 20 March 2020 and before 19 September 2020 are described in figures 2 and 3 and online supplemental table 3A,B. We observed substantial decline in percent of black patients over time in both individuals with COVID-19 (from $47.2 \%$ to $25.5 \%$, dropping by $21.7 \%$ ) and hospitalised individuals with COVID-19 (from $54.4 \%$ to $28.2 \%$, dropping by $26.3 \%$ ). The prevalence of comorbidities was consistently dropping between the two periods in individuals with COVID-19; the overall trend of comorbidity prevalence was still declining while less consistent in hospitalised individuals with COVID-19. In both of two cohorts, the percent of individuals living in disadvantaged neighbourhood (higher ADI) and COVID-19 testing capacity 


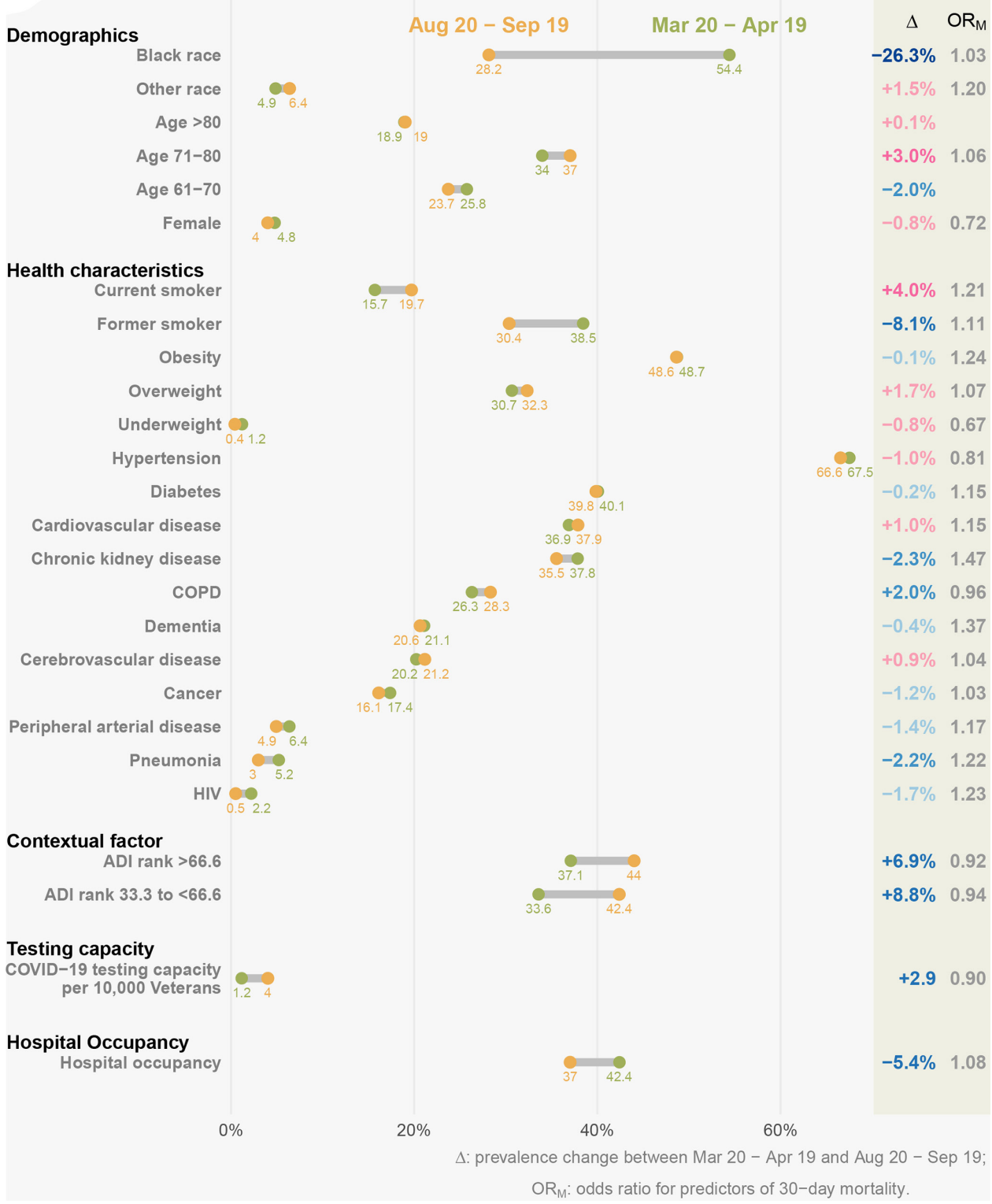

Figure 3 Change in predictors of 30-day mortality among hospitalised US veterans with COVID-19 between 20 March and 19 April 2020 and between 20 August and 19 September 2020. The yellow dots represent the prevalence of predictors in 20 March-19 April 2020, while the green dots represent the prevalence of predictors in 20 August-19 September 2020. In the $\Delta$ column, the blue text indicates that the change of predictor leads to decrease in mortality rates, while the red text indicates the change of predictor leads to decrease in mortality rates. ADI, Area Deprivation Index; COPD, chronic obstructive pulmonary disease.

were increasing over time, while hospital occupancy was decreasing.

\section{Contribution of changes in predictors to temporal changes in 30-day mortality and hospitalisation rates}

Decomposition analyses showed that from 20 March 2020 to 19 September 2020 and among COVID-19-positive individuals, changes in demographics, health characteristics, contextual characteristics, expansion of testing capacity and decreasing hospital occupancy contributed to $26.1 \%, 7.6 \%, 5.4 \%,-1.1 \%$ and $2.2 \%$ of the decline in 30-day mortality rates respectively. Altogether, these predictors accounted for $40.2 \%$ of the decline in 30-day mortality in veterans with COVID-19 (figure 4 and online supplemental table 4).

Changes in demographics, health characteristics and contextual characteristics, and expansion of testing capacity, and decreasing hospital occupancy contributed to $19.6 \%, 9.0 \%,-0.6 \%$ and $5.4 \%$ of the decline in hospitalisation rates. Altogether, they accounted for $33.3 \%$ of the decline in hospitalisation rates in veterans with COVID-19 (figure 4 and online supplemental table 4).

Among those hospitalised with COVID-19, changes in demographic, health characteristics, contextual characteristics, expansion of testing capacity and decreasing 


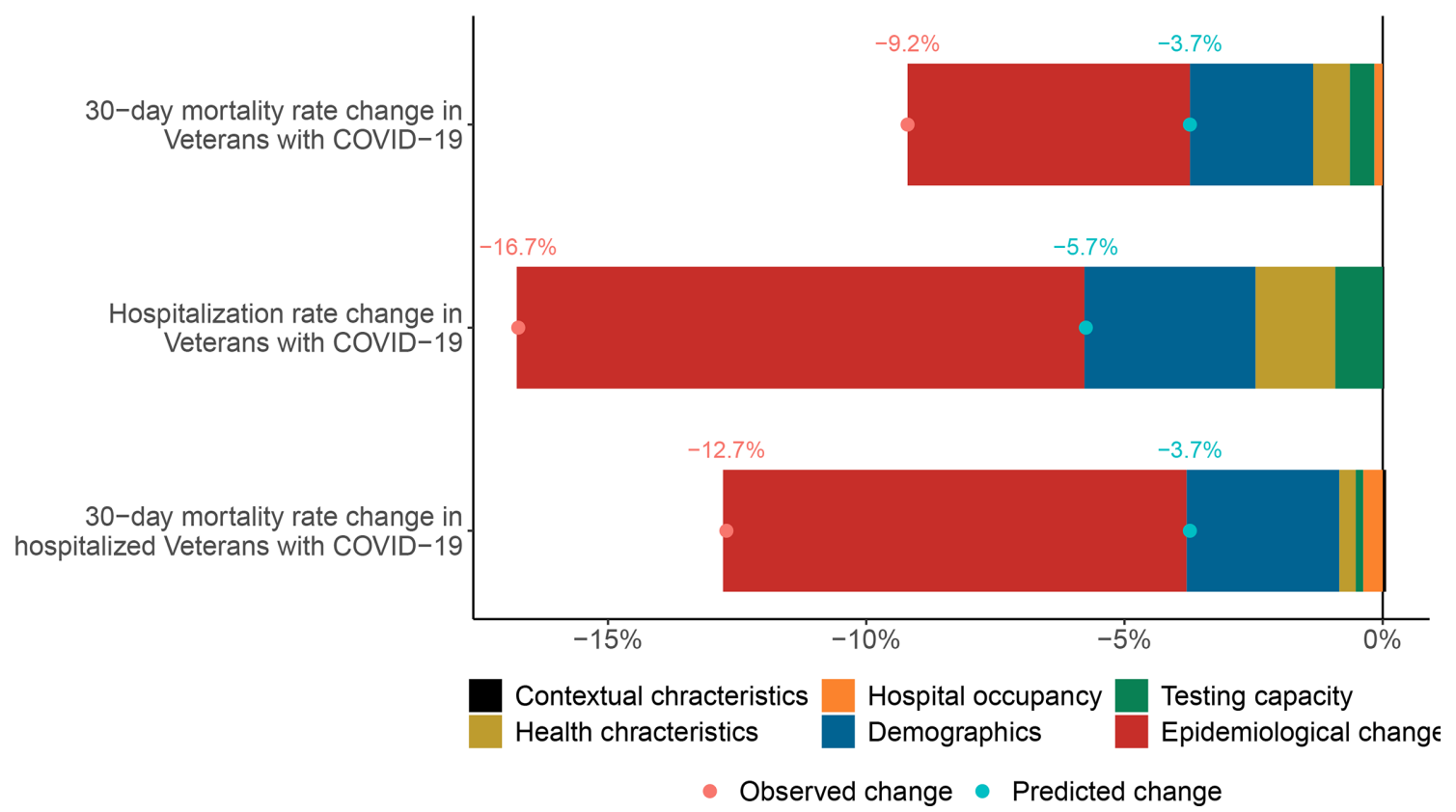

Figure 4 Contribution of changes in demographics, health characteristics, testing capacity, hospital occupancy and contextual factors, and epidemiological changes to changes in 30-day mortality and hospitalisation rates between 20 March and 19 April 2020 and between 20 August and 19 September 2020. The red dot represents the observed change in rate of outcomes between the two periods, and the blue dot represents the change predicted based on demographics, health, contextual characteristics, COVID-19 testing capacity and hospital occupancy. Hospital occupancy is not considered as predictor for the hospitalisation outcome model. Epidemiological changes collectively represent the difference between predicted and observed rates and reflect the summative contribution of factors that are not accounted for in prediction models.

hospital occupancy accounted for $23.6 \%, 2.4 \%,-0.8 \%$, $1.6 \%$ and $3.1 \%$ of the decline in 30-day mortality rate, respectively. All predictors collectively accounted for $29.9 \%$ of the decline in 30-day mortality (figure 4 and online supplemental table 4 ).

\section{DISCUSSION}

This analysis of temporal trends of COVID-19 hospitalisation and mortality suggests substantial decline between March 2020 and September 2020. We also observed substantial shifts in the demographic and health characteristics of those who tested positive for COVID-19 and in those who were hospitalised with a positive COVID-19 test including substantial decline in the percentage of black people and comorbidity burden as well as increase in testing capacity and reduction in hospital occupancy rates. Around $40.2 \%$ of the decline in mortality rates and $33.3 \%$ of decline in hospitalisation rates were explained by changes in the underlying characteristics of people who tested positive for COVID-19. Around 29.9\% of the decline in mortality rates among hospitalised individuals was explained by changes in their underlying characteristics.

Our analysis highlights the influence of individual-level demographic and health characteristics on hospitalisation and mortality rates in COVID-19. The contribution of changes in testing capacity to these outcomes (although small) was measurable. The contribution of hospital occupancy rates to decline in mortality rates also highlights the importance of this variable as policy makers and health systems continue to optimise the public health response to this pandemic and may also be useful in preparing for and mitigating the impact of future pandemics.

Slightly more than half of decline in rates was not predicted by the explanatory variables in our models and likely reflects the influence of factors that are not accounted for in our approach including improvement in medical care (to the extent that it may have influenced the outcomes), a putative seasonality effect and the potential influence of the broader public health policy measures on these outcomes. In particular, it has been postulated that severity of COVID-19 may be proportionate to the viral inoculum which initiates the infection in the human host, and it is plausible that public health policies (eg, physical distancing, masking, etc) may have reduced the viral inoculum in some infected individuals and might have consequently resulted in less severe COVID-19 (and reduced hospitalisation and mortality)-a hypothesis referred to as the variolation of coronavirus. ${ }^{29}$

Our findings not only provide insight into the dynamic changes of key indicators of the COVID-19 pandemic (mortality and hospitalisation rates) but also estimate of the influence of individual and contextual parameters on these indicators. The synergistic influence of both individual and contextual factors cannot be overstated. ${ }^{30} 31$ The COVID-19 pandemic has brought to prominence the complex interplay of several dynamic drivers including individual-level demographic and health characteristics, 
health system-level characteristics, the influence of socioeconomic factors and the broader contextual reality in which people live (public health response, etc) —all collectively shape the ultimate health outcomes of COVID-19. Continued effort to surveil temporal trends of key indicators of this global pandemic and careful analysis of drivers of any temporal change are needed to inform ongoing effort to optimise the management of this so far unabated pandemic and to guide development of better mitigation plans for future pandemics.

While we investigated the temporal trends of COVID-19 mortality and hospitalisation rates within the US veteran population, some important differences between our cohort and the general US population are noteworthy to better contextualise the broader implications of our findings. In our cohort, the median age was 63.6 years, the percentages of white and black race were $60.6 \%$ and $33.9 \%, 11.5 \%$ were women and $17.6 \%$ were current smokers; whereas in the US general population, the median age is 38.1 years, the percentages of white and black race are $60.1 \%$ and $13.4 \%, 50.8 \%$ are women and $13.7 \%$ are current smokers. ${ }^{32} 33$

A key strength of this analysis is the use of individuallevel data from the US Department of VA, which operates the largest nationally integrated healthcare system in the USA, and use of advanced methods to decompose the influence of changes in demographics and health characteristics on temporal trends. In addition to accounting for individual-level demographic and health characteristics, our analyses also accounted for contextual variables, testing capacity and measures of hospital occupancy rates-as important determinants of outcomes in this pandemic.

This analysis has several limitations. While we used validated definitions to identify covariates, we cannot completely rule out misclassification bias. While we accounted for known predictors, our analyses do not account for predictors that are not measured in the data sets including improvement in medical care as the pandemic progressed, and other unmeasured or unknown variables.

In sum, between March 2020 and September 2020, we observed substantial decline in 30-day mortality and hospitalisation among COVID-19-positive individuals and substantial decline in 30-day mortality among those hospitalised with COVID-19. The temporal decline in these outcomes was partially explained by changes in underlying demographic, health and contextual characteristics, as well as expansion of testing capacity, and reduction in hospital occupancy rates. The results may be helpful in informing effort to optimise the collective public health response to this ongoing pandemic and guide plans to mitigate the impact of future pandemics.

\section{Author affiliations}

${ }^{1}$ Clinical Epidemiology Center, VA Saint Louis Health Care System, Saint Louis, Missouri, USA
${ }^{2}$ Veterans Research and Education Foundation of Saint Louis, Saint Louis, Missouri, USA

${ }^{3}$ Department of Epidemiology and Biostatistics, College for Public Health and Social Justice, Saint Louis University, Saint Louis, Missouri, USA

${ }^{4}$ Institute for Public Health, Washington University in Saint Louis, Saint Louis, Missouri, USA

${ }^{5}$ Department of Medicine, Washington University School of Medicine, Saint Louis, Missouri, USA

${ }^{6}$ Nephrology Section, Medicine Service, VA Saint Louis Health Care System, Saint Louis, Missouri, USA

\section{Twitter Ziyad Al-Aly @zalaly}

Contributors Acquisition, analysis or interpretation of data, and statistical analysis: $M C, B B, Y X$ and $Z A-A$; drafting of the manuscript: $M C$ and $Z A-A$; supervision and funding: ZA-A; concept and design and critical revision of the manuscript for important intellectual content: all authors.

Funding This study was funded by the US Department of Veterans Affairs. The funders had no role in design and conduct of the study; collection, management, analysis and interpretation of the data; preparation, review or approval of the manuscript; and decision to submit the manuscript for publication.

Disclaimer The contents do not represent the views of the US Department of Veterans Affairs or the US government.

Competing interests None declared.

Patient consent for publication Not required.

Ethics approval The study was approved by the institutional review board of the VA St. Louis Health Care System, St. Louis, Missouri. The requirement for informed consent was waived as the risk to participants was intangible.

Provenance and peer review Not commissioned; externally peer reviewed.

Data availability statement The data that support the findings of this study are available from the VA. VA data are made available to researchers behind the VA firewall with an approved VA study protocol.

Supplemental material This content has been supplied by the author(s). It has not been vetted by BMJ Publishing Group Limited (BMJ) and may not have been peer-reviewed. Any opinions or recommendations discussed are solely those of the author(s) and are not endorsed by BMJ. BMJ disclaims all liability and responsibility arising from any reliance placed on the content. Where the content includes any translated material, BMJ does not warrant the accuracy and reliability of the translations (including but not limited to local regulations, clinical guidelines, terminology, drug names and drug dosages), and is not responsible for any error and/or omissions arising from translation and adaptation or otherwise.

Open access This is an open access article distributed in accordance with the Creative Commons Attribution Non Commercial (CC BY-NC 4.0) license, which permits others to distribute, remix, adapt, build upon this work non-commercially, and license their derivative works on different terms, provided the original work is properly cited, appropriate credit is given, any changes made indicated, and the use is non-commercial. See: http://creativecommons.org/licenses/by-nc/4.0/.

\section{ORCID iDs}

Miao Cai http://orcid.org/0000-0003-0170-6905

Yan Xie http://orcid.org/0000-0002-2457-9382

Ziyad Al-Aly http://orcid.org/0000-0002-2600-0434

\section{REFERENCES}

1 Center for Disease Control and Prevention, 2020COVIDView A Weekly Surveillance Summary of US COVID-19 Activity: Center for Disease Control and Prevention. Available: https://www.cdc.gov/ coronavirus/2019-ncov/covid-data/covidview/index.html2020

2 Dennis J, McGovern A, Vollmer S. Improving COVID-19 critical care mortality over time in England: a national cohort study. medRxiv 2020;2020.

3 Horwitz LI, Jones SA, Cerfolio RJ, et al. Trends in COVID-19 riskadjusted mortality rates. $J$ Hosp Med 2021;16:E1-3.

4 Bowe B, Cai M, Xie Y, et al. Acute kidney injury in a national cohort of hospitalized US veterans with COVID-19. Clin J Am Soc Nephrol 2020;16:14-25.

5 United States Department of Veteran Affairs. COVID-19:Shared Data Resource, 2020. Available: https://vhacdwdwhweb100.vha.med. 
va.gov/phenotype/index.php/COVID-19:Shared_Data_Resource\# Acknowledgements_COVID-19_Shared_Data_Resource

6 Bowe B, Xie Y, Xian H, et al. Geographic variation and US County characteristics associated with rapid kidney function decline. Kidney Int Rep 2017;2:5-17.

7 The Department of Veterans Affairs OolT. Corporate data Warehouse (CDW, 2014. Available: https://www.hsrd.research.va.gov/for_ researchers/vinci/cdw.cfm

8 Xie Y, Bowe B, Li T, et al. Long-Term kidney outcomes among users of proton pump inhibitors without intervening acute kidney injury. Kidney Int 2017;91:1482-94.

9 Xie Y, Bowe B, Li T, et al. Risk of death among users of proton pump inhibitors: a longitudinal observational cohort study of United States veterans. BMJ Open 2017;7:e015735.

10 Bowe B, Xie Y, Li T, et al. Associations of ambient coarse particulate matter, nitrogen dioxide, and carbon monoxide with the risk of kidney disease: a cohort study. Lancet Planet Health 2017;1:e267-76.

11 Bowe B, Xie Y, Li T, et al. Particulate matter air pollution and the risk of incident CKD and progression to ESRD. J Am Soc Nephrol 2018;29:218-30.

12 Bowe B, Xie Y, Li T, et al. Estimates of the 2016 global burden of kidney disease attributable to ambient fine particulate matter air pollution. BMJ Open 2019;9:e022450.

13 Bowe B, Xie Y, Xian H, et al. Association between monocyte count and risk of incident CKD and progression to ESRD. Clin J Am Soc Nephrol 2017;12:603-13.

14 Bowe B, Xie Y, Yan Y, et al. Burden of Cause-Specific Mortality Associated With PM Air Pollution in the United States. JAMA Netw Open 2019;2:e1915834.

15 Xie Y, Bowe B, Li T, et al. Higher blood urea nitrogen is associated with increased risk of incident diabetes mellitus. Kidney Int 2018;93:741-52.

16 Xie Y, Bowe B, Yan Y, et al. Estimates of all cause mortality and cause specific mortality associated with proton pump inhibitors among US veterans: cohort study. BMJ 2019;365:11580.

17 Al-Aly Z, Maddukuri G, Xie Y. Proton pump inhibitors and the kidney: implications of current evidence for clinical practice and when and how to deprescribe. Am J Kidney Dis 2020;75:497-507.

18 Cai M, Xie Y, Bowe B. Temporal trends in incidence rates of lower extremity amputation and associated risk factors among patients using Veterans health administration services from 2008 to 2018;4:e2033953.

19 Kind AJH, Buckingham WR. Making Neighborhood-Disadvantage Metrics Accessible - The Neighborhood Atlas. N Engl J Med 2018;378:2456-8
20 Cai M, Liu E, Zhang R, et al. Comparing the performance of Charlson and Elixhauser comorbidity indices to predict in-hospital mortality among a Chinese population. Clin Epidemiol 2020;12:307-16.

21 Levey AS, Stevens LA. Estimating GFR using the CKD epidemiology collaboration (CKD-EPI) creatinine equation: more accurate GFR estimates, lower CKD prevalence estimates, and better risk predictions. Am J Kidney Dis 2010;55:622-7.

22 Xie Y, Bowe B, Gibson AK, et al. Comparative effectiveness of SGLT2 inhibitors, GLP-1 receptor agonists, DPP-4 inhibitors, and sulfonylureas on risk of kidney outcomes: emulation of a target trial using health care databases. Diabetes Care 2020;43:2859-69.

23 Xie Y, Bowe B, Gibson AK, et al. Comparative effectiveness of the sodium-glucose cotransporter 2 inhibitor Empagliflozin versus other Antihyperglycemics on risk of major adverse kidney events. Diabetes Care 2020:43:2785-95.

24 Di Pino A, Scicali R, Calanna S, et al. Cardiovascular risk profile in subjects with prediabetes and new-onset type 2 diabetes identified by $\mathrm{HbA}(1 \mathrm{c})$ according to American Diabetes Association criteria. Diabetes Care 2014;37:1447-53.

25 Carey RM, Whelton PK, Committee A, 2017 ACC/AHA Hypertension Guideline Writing Committee. Prevention, detection, evaluation, and management of high blood pressure in adults: synopsis of the 2017 American College of Cardiology/American heart association hypertension guideline. Ann Intern Med 2018;168:351-8.

26 Curtin LR, Klein RJ. Direct standardization (age-adjusted death rates): US Department of Healthand Human Services, Public Health Service, Centers for Disease Control and Prevention. National Center for Health Statistics 1995.

27 Gupta PD. Standardization and decomposition of rates: a user's manual: US Department of Commerce, Economics and Statistics Administration Bureau; 1993.

28 R Core Team. R: A language and environment for statistical computing. Vienna, Austria, 2013

29 Gandhi M, Rutherford GW. Facial Masking for Covid-19 Potential for "Variolation" as We Await a Vaccine. N Engl J Med 2020;383:e101.

30 Xie Y, Bowe B, Maddukuri G. Comparative evaluation of clinical manifestations and risk of death in patients admitted to hospital with covid-19 and seasonal influenza: cohort study. BMJ;371.

31 Bowe B, Xie Y, Gibson AK, et al. Ambient fine particulate matter air pollution and the risk of hospitalization among COVID-19 positive individuals: cohort study. Environ Int 2021:154:106564.

32 Bowe B, Xie Y, Li T, et al. Changes in the US burden of chronic kidney disease from 2002 to 2016: an analysis of the global burden of disease study. JAMA Netw Open 2018;1:e184412:4412.

33 Xie Y, Bowe B, Yan Y, et al. County-Level contextual characteristics and disparities in life expectancy. Mayo Clin Proc 2021;96:92-104. 